\title{
Remote Oxygen Sensing by Ionospheric Excitation (ROSIE)
}

\author{
K. S. Kalogerakis ${ }^{1}$, T. G. Slanger ${ }^{1}$, E. A. Kendall ${ }^{2, *}$, T. R. Pedersen ${ }^{3}$, M. J. Kosch ${ }^{4}$, B. Gustavsson ${ }^{5}$, and M. T. Rietveld \\ ${ }^{1}$ Molecular Physics Laboratory, SRI International, Menlo Park, CA, USA \\ ${ }^{2}$ Center for Geospace Studies, SRI International, Menlo Park, CA, USA \\ ${ }^{3}$ Space Vehicles Directorate, Air Force Research Laboratory, Hanscom AFB, MA, USA \\ ${ }^{4}$ Communication Systems, Lancaster University, Lancaster, UK \\ ${ }^{5}$ Department of Physics and Technology, University of Troms $\varnothing$, Norway \\ ${ }^{6}$ EISCAT Scientific Association, Ramfjordmoen, Norway \\ *formerly Gerken
}

Received: 1 October 2008 - Revised: 29 April 2009 - Accepted: 29 April 2009 - Published: 13 May 2009

\begin{abstract}
The principal optical observable emission resulting from ionospheric modification (IM) experiments is the atomic oxygen red line at $630 \mathrm{~nm}$, originating from the $\mathrm{O}\left({ }^{1} \mathrm{D}-{ }^{3} \mathrm{P}\right)$ transition. Because the $\mathrm{O}\left({ }^{1} \mathrm{D}\right)$ atom has a long radiative lifetime, it is sensitive to collisional relaxation and an observed decay faster than the radiative rate can be attributed to collisions with atmospheric species. In contrast to the common practice of ignoring $\mathrm{O}$-atoms in interpreting such observations in the past, recent experimental studies on the relaxation of $\mathrm{O}\left({ }^{1} \mathrm{D}\right)$ by $\mathrm{O}\left({ }^{3} \mathrm{P}\right)$ have revealed the dominant role of oxygen atoms in controlling the lifetime of $\mathrm{O}\left({ }^{1} \mathrm{D}\right)$ at altitudes relevant to IM experiments. Using the most up-todate rate coefficients for collisional relaxation of $\mathrm{O}\left({ }^{1} \mathrm{D}\right)$ by $\mathrm{O}$, $\mathrm{N}_{2}$, and $\mathrm{O}_{2}$, it is now possible to analyze the red line decays observed in IM experiments and thus probe the local ionospheric composition. In this manner, we can demonstrate an approach to remotely detect $\mathrm{O}$-atoms at the altitudes relevant to IM experiments, which we call remote oxygen sensing by ionospheric excitation (ROSIE). The results can be compared with atmospheric models and used to study the temporal, seasonal, altitude and spatial variation of ionospheric $\mathrm{O}$-atom density in the vicinity of heating facilities. We discuss the relevance to atmospheric observations and ionospheric heating experiments and report an analysis of representative IM data.
\end{abstract}

Keywords. Atmospheric composition and structure (Airglow and aurora; Instruments and techniques) - Space plasma physics (Active perturbation experiments)

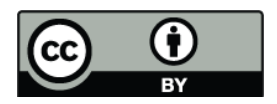

Correspondence to: K. S. Kalogerakis (ksk@sri.com)

\section{Introduction}

It has been a prime goal of optical aeronomy to make remote measurements of atmospheric emissions and deduce the atomic and molecular composition of the region being observed. A pre-eminent ionospheric emission, observed at all latitudes is that of the $\mathrm{O}\left({ }^{1} \mathrm{D}-{ }^{3} \mathrm{P}\right)$ oxygen red lines at 630.0 and $636.4 \mathrm{~nm}$. Because $\mathrm{O}\left({ }^{1} \mathrm{D}\right)$ is metastable with respect to radiation, with a radiative lifetime of $\sim 110$ s (Fischer and Saha, 1983; Fischer and Tachiev, 2004; Sharpee and Slanger, 2006), its loss is controlled by collisions with atmospheric species at altitudes below $300 \mathrm{~km}$. Therefore, a time-resolved measurement of its loss rate would provide information on the atmospheric composition, assuming that the relevant kinetic parameters are known. Ionospheric heating or ionospheric modification (IM) by high-power radiofrequency waves has been carried out for many years at various sites. It is a well known fact that in such experiments the $\mathrm{O}\left({ }^{1} \mathrm{D}\right)$ density is enhanced in the heated region (Bernhardt, 1988, 1989, 1991; Stubbe, 1996; Gurevich, 1997; Gustavsson, 2001, 2002; Kosch, 2007; Pedersen, 2008). The temporal evolution of the return to equilibrium in these experiments provides information on collisional loss, where the significant collider species are molecular nitrogen and oxygen atoms, the latter predominating above $\sim 200 \mathrm{~km}$.

Until recently, the lack of reliable information on the collisional role of $\mathrm{O}$-atoms has often led to the assumption that the red line decay was controlled by collisions with $\mathrm{N}_{2}$. Recent laboratory measurements at SRI International have established that the removal rate coefficients for $\mathrm{O}\left({ }^{1} \mathrm{D}\right)+\mathrm{N}_{2}$ and $\mathrm{O}\left({ }^{1} \mathrm{D}\right)+\mathrm{O}$ are comparable and therefore $\mathrm{O}$ atoms play a significant role in the ionospheric $\mathrm{O}\left({ }^{1} \mathrm{D}\right)$ decay (Closser, 2005; Kalogerakis, 2005, 2006; Slanger, 2006). Thus, measuring

Published by Copernicus Publications on behalf of the European Geosciences Union. 
Table 1. Rate coefficients for $\mathrm{O}\left({ }^{1} \mathrm{D}\right)$ relaxation by $\mathrm{O}\left({ }^{3} \mathrm{P}\right)$.

\begin{tabular}{lll}
\hline Rate coefficient, $k\left(\mathrm{~cm}^{3} \mathrm{~s}^{-1}\right)$ & Method & Reference \\
\hline$(8.0 \pm 7.0) \times 10^{-12}$ & Observation-Modeling & Abreu et al. (1986) \\
Rate coefficient insignificant & Observation-Modeling & Link and Cogger (1988) \\
$1 \times 10^{-11}(1000 \mathrm{~K})$ & Theory & Yee et al. (1990) \\
$6.9 \times 10^{-12}(1000 \mathrm{~K})$ & Theory & Sun et al. (1992) \\
$7.8 \times 10^{-12}(1000 \mathrm{~K})$ & Theory & Jamieson et al. (1992) \\
$9.2 \times 10^{-13}(750 \mathrm{~K})$ & Observation & Sobral et al. (1992) \\
Rate coefficient insignificant & Observation-Modeling & Semeter et al. (1996) \\
$(2.2 \pm 0.6) \times 10^{-11}(300 \mathrm{~K})$ & Experiment & Kalogerakis et al. (2006) \\
\hline
\end{tabular}

the red line decay following ionospheric excitation should provide a measure of the local $\mathrm{O}$-atom density, assuming that the contribution of $\mathrm{N}_{2}$ is known.

In this report, we present the relevant background to this approach, explore selected existing data sets from representative IM sites, determine the O-atom densities implied from the observed decays, and discuss the validity and relevance of this approach as a remote sensing technique for ionospheric $\mathrm{O}$-atom densities.

\section{Collisional relaxation of $\mathrm{O}\left({ }^{1} \mathrm{D}\right)$ by atmospheric species}

The atmospheric species relevant to collisional relaxation of $\mathrm{O}\left({ }^{1} \mathrm{D}\right)$ in the upper atmosphere are $\mathrm{N}_{2}, \mathrm{O}_{2}$, and $\mathrm{O}\left({ }^{3} \mathrm{P}\right)$. Given the rapid change of the $\mathrm{O}$-atom density in the mesosphere and lower thermosphere and the fact that $\mathrm{O}\left({ }^{3} \mathrm{P}\right)$ is the most abundant atmospheric species above $170 \mathrm{~km}$, it is critical to reliably establish the role of $\mathrm{O}$ atoms.

$\mathrm{N}_{2}$ efficiently relaxes $\mathrm{O}\left({ }^{1} \mathrm{D}\right)$ to its $\mathrm{O}\left({ }^{3} \mathrm{P}\right)$ ground state. Relatively recent NASA/JPL (Sander, 2003) and IUPAC recommendations (Atkinson, 2002) gave essentially the same value for the rate coefficient of $\mathrm{O}\left({ }^{1} \mathrm{D}\right)$ relaxation by $\mathrm{N}_{2}$ : $(2.6 \pm 1.0) \times 10^{-11} \mathrm{~cm}^{3} \mathrm{~s}^{-1}$ at $298 \mathrm{~K}(2 \sigma)$. However, a set of studies by Ravishankara and coworkers (Ravishankara 2002) measured a value of $(3.1 \pm 0.3) \times 10^{-11} \mathrm{~cm}^{3} \mathrm{~s}^{-1}$ at $295 \mathrm{~K}$ $(2 \sigma)$. This work was checked and compared in several laboratories (Ravishankara, 2002; Blitz, 2004; Dunlea, 2004; Strekowski, 2004) and has lately become the new NASA/JPL recommended value (Sander, 2006). As the temperature is increased to $1000 \mathrm{~K}$, the value of the rate coefficient decreases by approximately $20 \%$ (Ravishankara, 2002; Dunlea, 2004). For altitudes below $200 \mathrm{~km}, \mathrm{~N}_{2}$ is primarily responsible for collisional relaxation of $\mathrm{O}\left({ }^{1} \mathrm{D}\right)$.

Fast energy transfer from $\mathrm{O}\left({ }^{1} \mathrm{D}\right)$ to $\mathrm{O}_{2}$ relaxes $\mathrm{O}\left({ }^{1} \mathrm{D}\right)$ to $\mathrm{O}\left({ }^{3} \mathrm{P}\right)$ and generates the $v=0$ and $v=1$ levels of the $\mathrm{O}_{2}\left(b^{1} \Sigma_{g}^{+}\right)$ state. This process has a rate coefficient with a value of $(3.95 \pm 0.4) \times 10^{-11} \mathrm{~cm}^{3} \mathrm{~s}^{-1}$ (Sander, 2006). The role of molecular oxygen in the collisional relaxation of $\mathrm{O}\left({ }^{1} \mathrm{D}\right)$ is rather modest and limited to lower altitudes because of its relatively low atmospheric abundance.

As already mentioned, the interaction of $\mathrm{O}\left({ }^{1} \mathrm{D}\right)$ with $\mathrm{O}\left({ }^{3} \mathrm{P}\right)$ had not been investigated in the laboratory until recently, despite its overall importance in influencing the energy flow in the upper atmosphere. Theoretical calculations (Yee, 1990; Jamieson, 1992) and deduced values for the rate coefficient from atmospheric observations (Abreu, 1986; Sobral, 1992) differ by more than an order of magnitude. Table 1 presents a list of previous studies that have investigated the $\mathrm{O}\left({ }^{1} \mathrm{D}\right)+\mathrm{O}\left({ }^{3} \mathrm{P}\right)$ interaction. Theoretical calculations (Yee, 1990) and some observations (Abreu, 1986) of altitude profiles for the atomic oxygen red line emission have indicated that $\mathrm{O}\left({ }^{3} \mathrm{P}\right)$ atoms play an important role in relaxing $\mathrm{O}\left({ }^{1} \mathrm{D}\right)$ (with a rate coefficient of approximately $\left.1 \times 10^{-11} \mathrm{~cm}^{3} \mathrm{~s}^{-1}\right)$. Nevertheless, other investigators (Link, 1988, 1989; Solomon, 1989) interpret and model atmospheric observations without invoking the relaxation of $\mathrm{O}\left({ }^{1} \mathrm{D}\right)$ by $\mathrm{O}\left({ }^{3} \mathrm{P}\right)$. Semeter et al. (1996), in their analysis of the Release Experiments to Derive Airglow Inducing Reactions (RED AIR), concluded that quenching by $\mathrm{O}\left({ }^{3} \mathrm{P}\right)$ contributes very little to the depopulation of the nascent $\mathrm{O}\left({ }^{1} \mathrm{D}\right)$, with a value of zero giving the best fit to the RED AIR observations. Results of ionospheric heating experiments have been interpreted in terms of $\mathrm{O}\left({ }^{1} \mathrm{D}\right)$ quenching by $\mathrm{N}_{2}$ alone, with a minor contribution by $\mathrm{O}_{2}$ (Hernandez, 1972; Sipler, 1972; Bernhardt, 1988, 1989). It has only been relatively recently that $\mathrm{O}$-atom quenching has been seriously considered as an important process in the heating experiments (Bernhardt, 2000; Gustavsson, 2001). In retrospect, the problems caused by ignoring the role of oxygen atoms were foreshadowed by the conclusion that if $\mathrm{N}_{2}$ is the only quencher, then the rate coefficient for $\mathrm{O}\left({ }^{1} \mathrm{D}\right)$ quenching by $\mathrm{N}_{2}$ is $9 \times 10^{-11} \mathrm{~cm}^{3} \mathrm{~s}^{-1}$ (Hernandez, 1972), a value that we now know is unreasonably large. This is not the only example where the rate coefficient for $\mathrm{O}\left({ }^{1} \mathrm{D}\right)+\mathrm{N}_{2}$ has been largely overestimated in order to explain the IM observations (e.g., Sipler, 1972, 1974). From Table 1, it becomes clear that quantification of the red line emission has not been consistent in previous aeronomical studies. 
In recent experiments on $\mathrm{O}\left({ }^{1} \mathrm{D}\right)+\mathrm{O}\left({ }^{3} \mathrm{P}\right)$ at SRI International, we exploited the capabilities of our fluorine laser facility to measure the rate coefficient for collisional deactivation of $\mathrm{O}\left({ }^{1} \mathrm{D}\right)$ by $\mathrm{O}\left({ }^{3} \mathrm{P}\right)$ at room temperature. No other laboratory measurement of the rate coefficient of this process was available in the literature previously. In the experiments, a small amount of molecular oxygen mixed with helium carrier gas is photodissociated by the 157-nm output of the fluorine laser, generating $\mathrm{O}\left({ }^{1} \mathrm{D}\right)$ and $\mathrm{O}\left({ }^{3} \mathrm{P}\right)$ in equal amounts. The temporal evolution of the $\mathrm{O}\left({ }^{1} \mathrm{D}\right)$ concentration can be monitored by detection of the $630-\mathrm{nm}$ emission, and that of the $\mathrm{O}\left({ }^{3} \mathrm{P}\right)$ concentration can be monitored by two-photon laser-induced fluorescence (LIF). The results show that $\mathrm{O}\left({ }^{1} \mathrm{D}\right)$ relaxation by $\mathrm{O}\left({ }^{3} \mathrm{P}\right)$ has a rate coefficient of $(2.2 \pm 0.6) \times 10^{-11} \mathrm{~cm}^{3} \mathrm{~s}^{-1}$ $(2 \sigma)$ at room temperature (Closser, 2005; Kalogerakis, 2005, 2006). This value is larger by at least a factor of two than any previous estimate, whether from theory or observations. Theoretical calculations (Jamieson, 1992) indicate that the value of the rate coefficient at $1000 \mathrm{~K}$ is larger by approximately $25 \%$ than that at $300 \mathrm{~K}$. Laboratory experiments to study $\mathrm{O}\left({ }^{1} \mathrm{D}\right)+\mathrm{O}\left({ }^{3} \mathrm{P}\right)$ at elevated temperatures relevant to the lower thermosphere are planned for the future.

The magnitude of the rate coefficient indicates that relaxation of $\mathrm{O}\left({ }^{1} \mathrm{D}\right)$ by $\mathrm{O}\left({ }^{3} \mathrm{P}\right)$ is a fast process and must be taken into account in atmospheric models. Contrary to the analysis of Link and Cogger (1988), where it was concluded that the $\mathrm{O}\left({ }^{1} \mathrm{D}\right)+\mathrm{O}\left({ }^{3} \mathrm{P}\right)$ reaction was unnecessary to explain thermospheric $\mathrm{O}\left({ }^{1} \mathrm{D}\right)$ photochemistry, it is now clear that this is in fact the most important loss process for $\mathrm{O}\left({ }^{1} \mathrm{D}\right)$ over a large altitude range: from $200 \mathrm{~km}$, below which $\mathrm{N}_{2}$ quenching becomes dominant, up to $300 \mathrm{~km}$, above which radiation begins to dominate. Quite remarkably, the atmospheric implication of the $\mathrm{O}\left({ }^{1} \mathrm{D}\right)+\mathrm{O}\left({ }^{3} \mathrm{P}\right)$ rate coefficient is that at least $50 \%$ of the $\mathrm{O}\left({ }^{1} \mathrm{D}\right)$ removal occurs by collisions with $\mathrm{O}\left({ }^{3} \mathrm{P}\right)$ at an altitude of $\sim 250 \mathrm{~km}$ (radiation and $\mathrm{N}_{2}$ contribute $\sim 25 \%$ each) and at least $15 \%$ of the $\mathrm{O}\left({ }^{1} \mathrm{D}\right)$ removal occurs by collisions with $\mathrm{O}\left({ }^{3} \mathrm{P}\right)$ as high as $400 \mathrm{~km}$ (radiation accounts for the remaining $\sim 85 \%$ ). Figure 1 summarizes the picture that has emerged for $\mathrm{O}\left({ }^{1} \mathrm{D}\right)$ relaxation in the upper atmosphere. The atmospheric composition and temperature profiles are generated using the MSIS-E-90 atmospheric model (Hedin, 1991). The contributions of $\mathrm{O}_{2}$ and $\mathrm{N}_{2}$ in $\mathrm{O}\left({ }^{1} \mathrm{D}\right)$ relaxation were calculated based on the published rate coefficients and their temperature (altitude) dependence (Ravishankara, 2002; Blitz, 2004; Dunlea, 2004; Sander, 2006). We note that for the rate coefficient for $\mathrm{O}\left({ }^{1} \mathrm{D}\right)$ relaxation by $\mathrm{O}\left({ }^{3} \mathrm{P}\right)$, we have used the SRI laboratory result at room temperature with a temperature dependence as predicted by theoretical calculations (Jamieson, 1992). Other calculations for this process performed on different potential energy curves have shown the same trend in the temperature dependence (Saxon, 1977; Yee, 1990). To the best of our knowledge, no experimental information is available on the temperature dependence of $\mathrm{O}\left({ }^{1} \mathrm{D}\right)$ relaxation by $\mathrm{O}\left({ }^{3} \mathrm{P}\right)$.

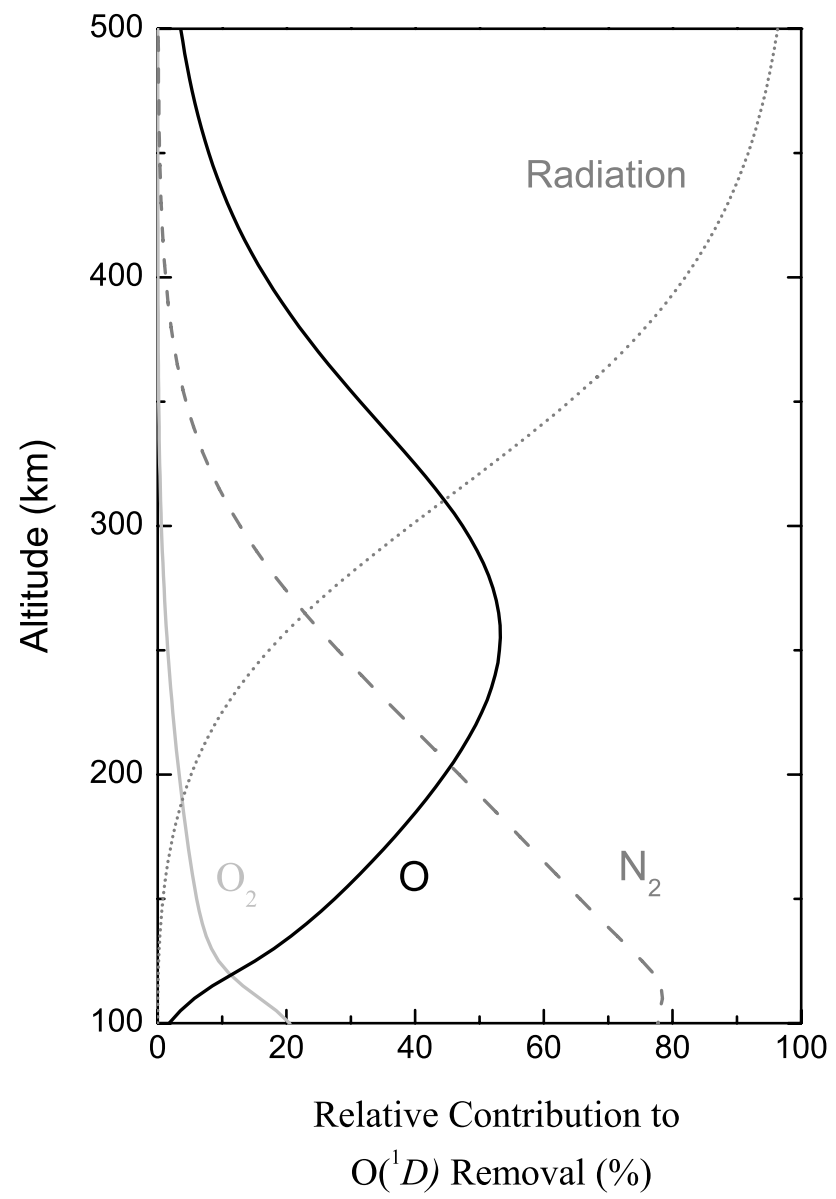

Fig. 1. Calculated relative contribution to $O\left({ }^{1} \mathrm{D}\right)$ loss as a function of altitude by $\mathrm{O}$ (solid black line), $\mathrm{O}_{2}$ (solid grey line), $\mathrm{N}_{2}$ (dashed grey line) and radiative decay (dotted grey line). These four processes are assumed to be the only pathways for $\mathrm{O}\left({ }^{1} \mathrm{D}\right)$ relaxation. The atmospheric composition is based on the MSIS-E-90 model (Hedin, 1991).

\section{Results from ionospheric modification experiments and discussion}

Typical altitudes probed by IM experiments are in the range 250-300 km. From Fig. 1, it becomes clear that if we use lifetime and altitude data collected during an IM experiment we can determine whether a consistent picture emerges from the atmospheric models. Given the relatively low abundance of electrons or other ionized species, it is reasonable to assume that neutral species have the dominant role in the relaxation of $\mathrm{O}\left({ }^{1} \mathrm{D}\right)$. The observed rate of decay for $\mathrm{O}\left({ }^{1} \mathrm{D}\right) \mathrm{can}$ be expressed as:

$\tau^{-1}=\tau_{R}^{-1}+k_{O}\left[\mathrm{O}\left({ }^{3} \mathrm{P}\right)\right]+k_{\mathrm{N} 2}\left[\mathrm{~N}_{2}\right]+k_{\mathrm{O} 2}\left[\mathrm{O}_{2}\right]$,

where $\tau$ is the observed $\mathrm{O}\left({ }^{1} \mathrm{D}\right)$ lifetime as a function of altitude in the IM measurement, $\tau_{R}$ is the $\mathrm{O}\left({ }^{1} \mathrm{D}\right)$ radiative lifetime, $k_{O}, k_{N 2}$, and $k_{O 2}$ are the rate coefficients for collisional relaxation of $\mathrm{O}\left({ }^{1} \mathrm{D}\right)$ by $\mathrm{O}\left({ }^{3} \mathrm{P}\right), \mathrm{N}_{2}$, and $\mathrm{O}_{2}$, and $\left[\mathrm{O}\left({ }^{3} \mathrm{P}\right)\right],\left[\mathrm{N}_{2}\right]$, 


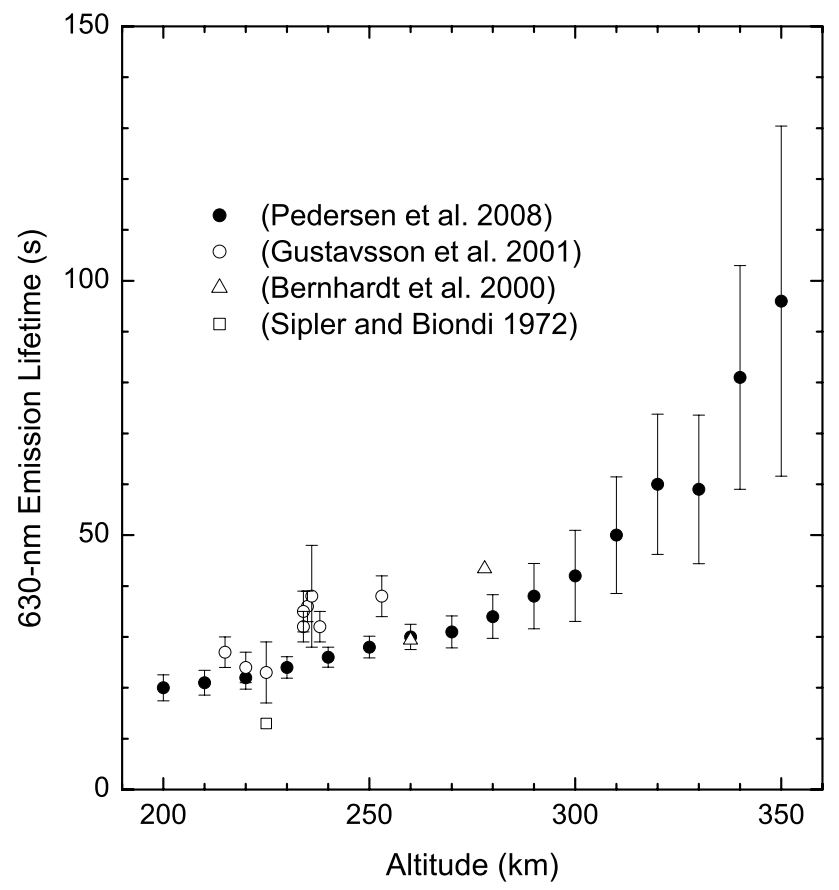

Fig. 2a. Observed $O\left({ }^{1} \mathrm{D}\right)$ lifetime values as a function of altitude for representative IM experiments.

and $\left[\mathrm{O}_{2}\right]$ are the local $\mathrm{O}\left({ }^{3} \mathrm{P}\right), \mathrm{N}_{2}$, and $\mathrm{O}_{2}$ densities, respectively.

Figure 2a presents examples of existing IM data sets from EISCAT (Gustavsson 2001), HAARP (Pedersen, 2008), Platteville (Sipler and Biondi, 1972), and SURA (Bernhardt, 2000). These experiments probe an extensive range of ionospheric altitudes from $200 \mathrm{~km}$ to $350 \mathrm{~km}$. Reliable knowledge of the altitude of the induced optical emissions has been problematic for many of the older data sets since the beginning of IM experiments in the late 1960s. Recent improvements in data analysis techniques, as well as the availability of modern optical monitoring infrastructure networks near EISCAT and HAARP have enabled a more accurate determination of the optical emission intensity distribution as a function of altitude (Gustavsson, 2001; Pedersen, 2008). The most extensive data set is the recent study from HAARP (Pedersen, 2008), which covers a large range of altitudes (200-350 km).

In Fig. $2 b$, the observed $\mathrm{O}\left({ }^{1} \mathrm{D}\right)$ lifetimes for the HAARP data set are compared with model calculations using Eq. (1). The atmospheric composition (i.e., $\left[\mathrm{N}_{2}\right],\left[\mathrm{O}_{2}\right]$, and $[\mathrm{O}]$ ) is estimated using the MSIS-E-90 model for conditions specific to the HAARP data set (4 February 2005, 04:00 UT, $62.4^{\circ} \mathrm{N}, 145^{\circ} \mathrm{W}, \mathrm{F} 10.7=80.7$, ap $=3.1$ ). We use the best available rate coefficients for $\mathrm{O}\left({ }^{1} \mathrm{D}\right)$ relaxation by $\mathrm{N}_{2}$ and $\mathrm{O}_{2}$ as described in the previous section. We use three different values of the rate coefficient for $\mathrm{O}\left({ }^{1} \mathrm{D}\right)+\mathrm{O}\left({ }^{3} \mathrm{P}\right): k_{O}=0 \mathrm{~cm}^{3} \mathrm{~s}^{-1}$ (no relaxation by $\mathrm{O}$ atoms), $k_{O}=2.5 \times 10^{-12} \mathrm{~cm}^{3} \mathrm{~s}^{-1}$, and

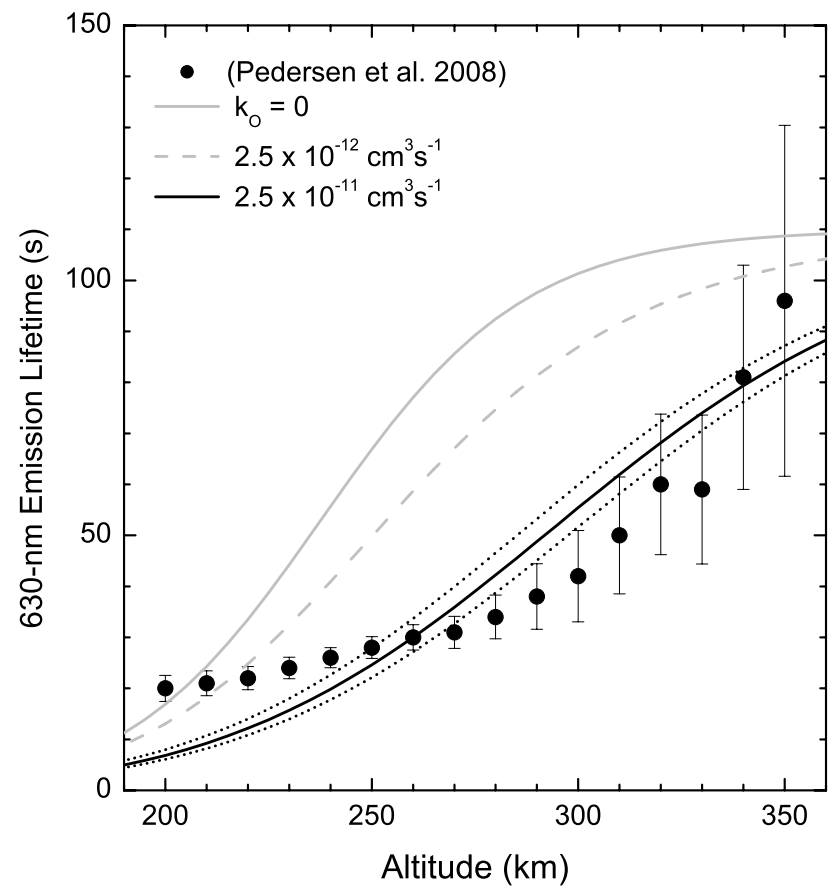

Fig. 2b. Observed and calculated $\mathrm{O}\left({ }^{1} \mathrm{D}\right)$ lifetimes for the HAARP data set (solid black circles). The solid grey line, dashed grey line, and solid black line represent the calculated values, as deduced from Eq. (1), for different values of $k_{O}$. The black dotted lines accompanying the black solid line reflect the range of lifetime values calculated for an estimated $15 \%$ uncertainty in the rate coefficients.

$k_{O}=2.5 \times 10^{-11} \mathrm{~cm}^{3} \mathrm{~s}^{-1}$ (based on the value of our roomtemperature experimental study adjusted for thermospheric temperatures at $200-350 \mathrm{~km}$ ). The solid black circles represent the $\mathrm{O}\left({ }^{1} \mathrm{D}\right)$ lifetimes reported in the HAARP data set (Pedersen, 2008). The solid grey line, dashed grey line, and solid black line present the calculated values, as deduced from Eq. (1), for $k_{O}=0 \mathrm{~cm}^{3} \mathrm{~s}^{-1}, k_{O}=2.5 \times 10^{-12} \mathrm{~cm}^{3} \mathrm{~s}^{-1}$, and $k_{O}=2.5 \times 10^{-11} \mathrm{~cm}^{3} \mathrm{~s}^{-1}$, respectively. The black dotted lines accompanying the black solid line reflect the range of lifetime values calculated for an estimated $15 \%$ uncertainty in the rate coefficients. No adjustable parameter is used in any of the calculations presented in the figure. Clearly, the best agreement between calculated and observed lifetimes occurs for $k_{O}=2.5 \times 10^{-11} \mathrm{~cm}^{3} \mathrm{~s}^{-1}$. As already shown in Fig. 1, collisional relaxation of $\mathrm{O}\left({ }^{1} \mathrm{D}\right)$ by oxygen atoms is expected to play the most important role in the altitude range $200-300 \mathrm{~km}$, with radiative decay dominating above $\sim 300 \mathrm{~km}$ and, relaxation by molecular nitrogen taking over below $\sim 200 \mathrm{~km}$. However, the observed $\mathrm{O}\left({ }^{1} \mathrm{D}\right)$ decay rates in the range $200-250 \mathrm{~km}$ in the IM experiments shown are consistently smaller than the calculated ones. One limitation at the lower altitudes is that the temporal resolution of the measurements is comparable (or worse in some cases) to the $\mathrm{O}\left({ }^{1} \mathrm{D}\right)$ effective lifetime. Below, we briefly discuss some relevant effects that may be the cause for this discrepancy. 


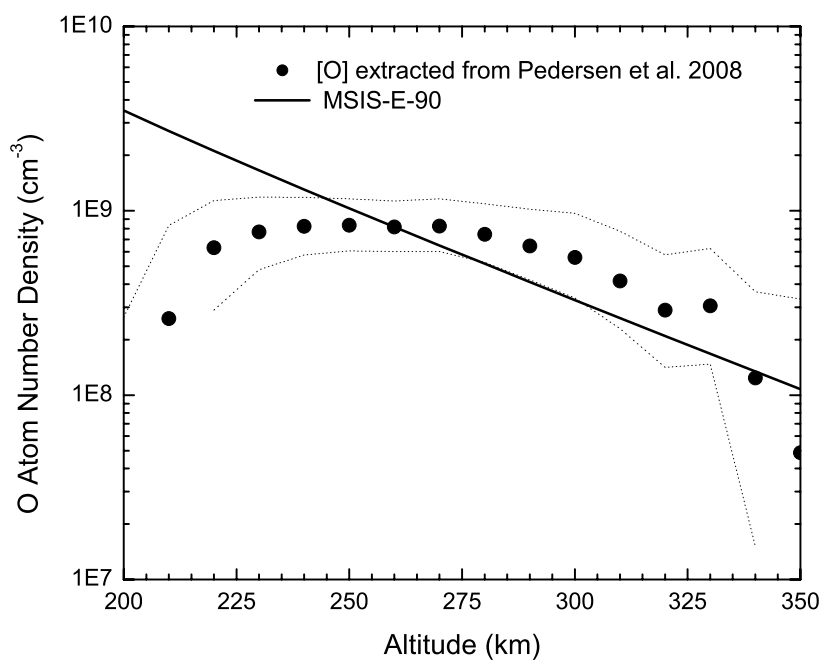

Fig. 3. O-atom number density as a function of altitude, determined from the observations by Pedersen et al. (2008) at HAARP. The dashed line reflects the reported lifetime uncertainty and the thick solid line represents the MSIS-E-90 atmospheric model.

Given the observed $\mathrm{O}\left({ }^{1} \mathrm{D}\right)$ decay rate, we can solve Eq. (1) to determine the $\mathrm{O}$-atom density, $[\mathrm{O}]$, using the atmospheric composition for $\left[\mathrm{N}_{2}\right]$ and $\left[\mathrm{O}_{2}\right]$, and the rate coefficient values used in the calculations of Fig. 2. Figure 3 presents the results of this calculation for the most recent and extensive set of IM data from HAARP (Pedersen, 2008). The solid line presents the predictions of the MSIS-E-90 model for the number density of oxygen atoms. As already seen in Fig. 2, the altitude region with the best agreement with the standard atmosphere is above approximately $250 \mathrm{~km}$, with a significant systematic deviation below $250 \mathrm{~km}$.

The satisfactory agreement between predictions and observations in a broad range of altitudes supports the notion that IM measurements can be used to probe the upper atmospheric composition, and more specifically, the O-atom density. Nevertheless, the deviations at lower altitudes highlight the need to develop a detailed understanding of several relevant effects and interactions, such as the dependence on the power of the RF radiation. Very intense fields might significantly perturb the local atmospheric composition of neutral or ionic species. The possibility of secondary ion chemistry and delayed production of $\mathrm{O}\left({ }^{1} \mathrm{D}\right)$ would increase its effective lifetime. The geomagnetic history before IM measurements may also influence the local atmospheric composition and the observed emissions, as well as the geometry of excitation for heating facilities at different latitudes (the latitude range for the examples shown in Fig. 2 is from $49^{\circ} \mathrm{N}$ for Platteville to $69.6^{\circ} \mathrm{N}$ for EISCAT). Of special interest are the mechanism(s) generating the optical emissions (Kosch, 2007; Gustavsson and Eliasson, 2008). The details of these mechanisms (e.g., dependence on altitude, RF power, geomagnetic history) are not fully understood. Systematic studies at high- temporal resolution are needed to elucidate the role of all the aforementioned parameters.

Understanding processes involving atomic oxygen is crucial for the study of energy transfer and transport dynamics in the upper atmosphere. Determining the O-atom density in the upper atmosphere has been a long-standing and challenging problem. Being able to remotely sense and study the O-atom density fluctuations, spatial distribution, seasonal and temporal variability are important goals in the field of aeronomy. Finally, the ability to probe ionospheric O-atom densities is relevant to satellite drag, in view of the fact that at IM altitudes, cf. $300 \mathrm{~km}$, the $\mathrm{O}\left({ }^{1} \mathrm{D}\right)$ decay also provides a measure of the total density.

\section{Conclusions}

Between approximately $200 \mathrm{~km}$ and $300 \mathrm{~km}, \mathrm{O}$ atoms control the atomic oxygen red line emission and must be taken into account for the analysis or IM experiments. The observed $\mathrm{O}\left({ }^{1} \mathrm{D}\right)$ lifetime in IM experiments provides a measure of the local O-atom density. An analysis of existing IM data yields good agreement between observations and the MSIS-E-90 model for altitudes above $250 \mathrm{~km}$. Once the relevant details are better understood for establishing the optimal conditions for which IM measurements can be used as a probe for [O], it will be possible to investigate the climatology of ionospheric $\mathrm{O}\left({ }^{3} \mathrm{P}\right)$ in the vicinity of IM sites. Finally, this work highlights the fruitful interplay and synergy between fundamental laboratory measurements and field aeronomy.

Acknowledgements. This work is supported by the CEDAR Program of the US National Science Foundation under grant no. ATM0737713. Work at AFRL was supported by AFOSR task 2311AS. We are indebted to the ISEA-12 committee for the opportunity to present our research and for their efforts in organizing a high-quality meeting. Finally, we thank two anonymous reviewers for their comments and suggestions.

Topical Editor K. Kauristie thanks two anonymous referees for their help in evaluating this paper.

\section{References}

Atkinson, R., Baulch, D. L., Cox, R. A., Crowley, J., Hampson, R. F., Jenkins, M. E., Kerr, J. A., Rossi, M. J., and Troe, J.: IUPAC Subcommittee for Gas Kinetic Data Evaluation, Evaluated kinetic data, http://www.iupac-kinetic.ch.cam.ac.uk/, 2002.

Abreu, V. J., Yee, J. H., Solomon, S. C., and Dalgarno, A.: The quenching rate of $\mathrm{O}\left({ }^{1} \mathrm{D}\right)$ by $\mathrm{O}\left({ }^{3} \mathrm{P}\right)$, Planet. Space Sci., 34, $1143-$ $1145,1986$.

Bernhardt, P. A., Duncan, L. M., Tepley, C. A., Behnke, R. A., and Sheerin, J. P.: Spatial and temporal evolution of $630.0 \mathrm{~nm}$ airglow enhancements during ionospheric heating experiments, Adv. Space Res., 8, 271-277, 1988.

Bernhardt, P. A., Tepley, C. A., and Duncan, L. M.: Airglow enhancements during ionospheric heating experiments, J. Geophys. Res., 94(A7), 9071-9092, 1989. 
Bernhardt, P. A., Scales, W. A., Grach, S. M., Keroshtin, A. N., Kotik, D. S., and Polyakov, S. V.: Excitation of artificial airglow by high power radio waves from the 'SURA' Ionospheric Heating Facility, Geophys. Res. Lett., 18, 1477-1480, 1991.

Bernhardt, P. A., Wong, M., Huba, J. D., Fejer, B. G., Wagner, L. S., Goldstein, J. A., Selcher, C. A., Frolov, V. L., and Sergeev, E. N.: Optical remote sensing of the thermosphere with HF pumped artificial airglow, J. Geophys. Res., 105, 10657-10671, 2000.

Blitz, M. A., Dillon, T. J., Heard, D. E., Pilling, M. J., and Trought, I. D.: Laser induced fluorescence studies of the reactions of $\mathrm{O}\left({ }^{1} D_{2}\right)$ with $\mathrm{N}_{2}, \mathrm{O}_{2}, \mathrm{~N}_{2} \mathrm{O}, \mathrm{CH}_{4}, \mathrm{H}_{2}, \mathrm{CO}_{2}, \mathrm{Ar}, \mathrm{Kr}$, and n- $\mathrm{C}_{4} \mathrm{H}_{10}$, Phys. Chem. Chem. Phys., 6, 2162-2171, 2004.

Closser, K. D., Pejakovic, D. A., and Kalogerakis, K. S.: $\mathrm{O}\left({ }^{1} \mathrm{D}\right)$ relaxation by $\mathrm{O}\left({ }^{3} \mathrm{P}\right)$, EOS Trans. AGU, 86(52) Fall Meet. Suppl., Abstract SA11A-0215, 2005.

Dunlea, E. J. and Ravishankara, A. R.: Kinetic studies of the reactions of $\mathrm{O}\left({ }^{1} \mathrm{D}\right)$ with several atmospheric molecules, Phys. Chem. Chem. Phys., 6, 2152-2161, 2004.

Fischer, C. F. and Saha, H.: Multiconfiguration Hartree-Fock results with Breit-Pauli corrections for forbidden transitions in the $2 p^{4}$ configuration, Phys. Rev. A, 28, 3169-3178, 1983.

Fischer, C. F. and Tachiev., G.: Breit-Pauli energy levels, lifetimes, and transition probabilities for the beryllium-like to neon-like sequences, At. Data Nucl. Data Tables, 87, 1-184, 2004.

Gurevich, A. V. and Milikh, G. M.: Artificial airglow due to modifications of the ionosphere by powerful radio waves, J. Geophys. Res., 102, 389-394, 1997.

Gustavsson, B., Sergienko, T., Rietveld, M. T., Honary, F., Steen, A., Braendstroem, B. U. E., Leyser, T. B., Aruliah, A. L., Aso, T., Ejiri, M., and Marple, S.: First tomographic estimate of volume distribution of enhanced airglow emission caused by HF pumping, J. Geophys. Res., 106, 29105-29123, 2001.

Gustavsson, B., Braendstroem, B. U. E., Steen, A., et al.: Nearly simultaneous images of HF-pump enhanced airglow at $6300 \AA$ and $5577 \AA$, Geophys. Res. Lett., 29, 2220, doi:10.1029/2002GL015350, 2002.

Gustavsson, B. and Eliasson, B.: HF radio wave acceleration of ionospheric electrons: Analysis of HF-induced optical enhancements, J. Geophys. Res., 113, A08319, doi:10.1029/2007JA012913, 2008

Hedin, A. E.: Extension of the MSIS thermospheric model into the middle and lower atmosphere, (The model can be run online at http://ccmc.gsfc.nasa.gov/modelweb/atmos/msise.html), J. Geophys. Res., 96, 1159-1172, 1991.

Hernandez, G.: Determination of the quenching of $\mathrm{O}\left({ }^{1} \mathrm{D}\right)$ by molecular nitrogen using the ionospheric modification experiment, $\mathrm{J}$. Geophys. Res., 77, 3625-3629, 1972.

Jamieson, M. J., Finch, M., Friedman, R. S., and Dalgarno, A.: Collisional excitation of metastable oxygen $\mathrm{O}\left({ }^{1} \mathrm{D}\right)$ atoms through the $B^{3} \Sigma_{u}^{-}$channel of $\mathrm{O}_{2}$, Planet. Space Sci., 40, 1719-1721, 1992.

Kalogerakis, K. S., Pejakovic, D. A., Copeland, R. A., and Slanger, T. G.: The rate coefficient of $\mathrm{O}\left({ }^{1} \mathrm{D}\right)$ relaxation by $\mathrm{O}\left({ }^{3} \mathrm{P}\right), 2005$ CEDAR-GEM Workshop, Santa Fe, New Mexico, 26 June-1 July 2005 .

Kalogerakis, K. S., Pejakovic, D. A., and Closser, K. D.: $\mathrm{O}\left({ }^{1} \mathrm{D}\right)$ relaxation by $\mathrm{O}\left({ }^{3} \mathrm{P}\right)$, Geophys. Res. Abstr., 8, 9689, 2006.

Kosch, M. J., Pedersen, T., Rietveld, M. T., Gustavsson, B., Grach, S. M., and Hagfors, T.: Artificial optical emissions in the thermosphere induced by powerful radio waves:
An observational review, Adv. Space Res., 40, 365-376, doi:10.1016/j.asr.2007.02.061, 2007.

Link, R. and Cogger, L. L.: A Re-examination of the OI $6300 \AA$ Nightglow, J. Geophys. Res., 93, 9883-9892, 1988.

Link, R. and Cogger, L. L.: Erratum: A Re-examination of the OI 6300 Å Nightglow, J. Geophys. Res., 94, 1556, 1989.

Pedersen, T., Esposito, R., Kendall, E., Sentman, D., Kosch, M., Mishin, E., and Marshall, R.: Observations of artificial and natural optical emissions at the HAARP facility, Ann. Geophys., 26, 1089-1099, 2008, http://www.ann-geophys.net/26/1089/2008/.

Ravishankara, A. R., Dunlea, E. J., Blitz, M. A., Dillon, T. J., Heard, D. E., Pilling, M. J., Strekowski, R. S., Nicovich, J. M., and Wine, P. H.: Redetermination of the Rate Coefficient for the Reaction of $\mathrm{O}\left({ }^{1} \mathrm{D}\right)$ with $\mathrm{N}_{2}$, Geophys. Res. Lett., 29, 1745, doi:10.1029/2002GL014850, 2002, 2002.

Rietveld, M. T., Kosch, M. J., Blagoveshchenskaya, N. F., et al.: Ionospheric electron heating, optical emissions, and striations induced by powerful HF radio waves at high latitudes: Aspect angle dependence, J. Geophys. Res., 108(A4), 1141, doi:10.1029/2002JA009543, 2003.

Robinson, T. R.: The heating of the high latitude ionosphere by high power radio waves, Physics Rep., 179, 79-209, 1989.

Sander, S. P., Friedl, R. R., Golden, D. M., Kurylo, M. J., Huie, R. E., Orkin, V. L., Moortgat, G. K., Ravishankara, A. R., Kolb, C. E., Molina, M. J., and Finlayson-Pitts, B. J.: Chemical kinetics and photochemical data for use in stratospheric modeling, Evaluation No. 14, National Aeronautics and Space Administration, Jet Propulsion Laboratory, 2003.

Sander, S. P., Friedl, R. R., Golden, D. M., Kurylo, M. J., Huie, R. E., Orkin, V. L., Moortgat, G. K., Ravishankara, A. R., Kolb, C. E., Molina, M. J., and Finlayson-Pitts, B. J.: Chemical kinetics and photochemical data for use in stratospheric modeling, Evaluation Number 15, National Aeronautics and Space Administration, Jet Propulsion Laboratory, 2006.

Saxon, R. P. and Liu, B. J.: Ab initio configuration interaction study of the valence states of $\mathrm{O}_{2}$, Chem. Phys., 67, 5432-5441, 1977.

Semeter, J., Mendillo, M., Baumgardner, J., Holt, J., Hunton, D. E., and Eccles, V.: A study of oxygen $6300 \AA$ airglow production through chemical modification of the nighttime ionosphere, J. Geophys. Res., 101(A9), 19683-19699, 1996.

Sharpee, B. D. and Slanger, T. G.: $\mathrm{O}\left({ }^{1} D_{2}-{ }^{3} P_{2,1,0}\right)$ 630.0, 636.4, 636.4, and $639.2 \mathrm{~nm}$ forbidden emission line intensity ratios measured in the Terrestrial nightglow, J. Phys. Chem. A, 110, 6707-6710, 2006.

Sipler, D. P. and Biondi, M. A.: Measurements of $\mathrm{O}\left({ }^{1} \mathrm{D}\right)$ quenching rates in the F region, J. Geophys. Res., 77, 6202-6212, 1972.

Sipler, D. P., Enemark, E., and Biondi, M. A.:, 6300- $\AA$ intensity variations produced by the Arecibo ionospheric modification experiment, J. Geophys. Res., 79, 4276-4280, 1974.

Slanger, T. G.: Studies of ionospheric processes in the atmosphere and the laboratory, URSI/NATO Conference, Fairbanks, Alaska, 12-16 June 2006.

Sobral, J. H. A., Takahashi, H., Abdu, H., Murelikrishna, P., Sahai, P., and Zamlutti, C. J.: $\mathrm{O}\left({ }^{1} \mathrm{~S}\right)$ and $\mathrm{O}\left({ }^{1} \mathrm{D}\right)$ yields from rocket measurements of electron densities and 557.5 and $630.0 \mathrm{~nm}$ emissions in the nocturnal $F$-region, Planet. Space Sci., 40, 607-619, 1992.

Solomon, S. C. and Abreu, V. J.: The $630 \mathrm{~nm}$ dayglow, J. Geophys. Res., 94, 6817-6824, 1989. 
Strekowski, R. S., Nicovich, J. M., and Wine, P. H.: Temperaturedependent kinetics study of the reactions of $\mathrm{O}\left({ }^{1} \mathrm{D}_{2}\right)$ with $\mathrm{N}_{2}$ and $\mathrm{O}_{2}$, Phys. Chem. Chem. Phys., 6, 2145-2151, 2004.

Stubbe, P.: Review of ionospheric modification experiments at Tromsø, J. Atmos. Terr. Phys., 58, 349-368, 1996.
Sun, Y. and Dalgarno, A.: Collisional excitation of metastable $\mathrm{O}\left({ }^{1} \mathrm{D}\right)$ atoms, J. Chem. Phys., 96, 5017-5019, 1992.

Yee, J.-H., Guberman, S. L., and Dalgarno, A.: Collisional quenching of $\mathrm{O}\left({ }^{1} \mathrm{D}\right)$ by $\mathrm{O}\left({ }^{3} \mathrm{P}\right)$, Planet. Space Sci., 38, 647-652, 1990. 